\title{
Adaptive Interactions of Achromobacter spp. with Pseudomonas aeruginosa in Cystic Fibrosis Chronic Lung Co-Infection
}

\author{
Angela Sandri ${ }^{1}{ }^{(0}$, Janus Anders Juul Haagensen ${ }^{2}$, Laura Veschetti ${ }^{3}{ }^{\oplus}$, Helle Krogh Johansen ${ }^{4,5}{ }^{\oplus}$, Søren Molin ${ }^{2}$, \\ Giovanni Malerba ${ }^{3}{ }^{(D}$, Caterina Signoretto ${ }^{1}$, Marzia Boaretti ${ }^{1,+}$ and Maria M. Lleo ${ }^{1, *,+}$ \\ 1 Department of Diagnostics and Public Health, Section of Microbiology, University of Verona, Strada Le \\ Grazie 8, 37134 Verona, Italy; angela.sandri@univr.it (A.S.); caterina.signoretto@univr.it (C.S.); \\ marzia.boaretti@univr.it (M.B.) \\ 2 Novo Nordisk Foundation Center for Biosustainability, Technical University of Denmark, \\ 2800 Kgs. Lyngby, Denmark; jajh@biosustain.dtu.dk (J.A.J.H.); sm@bio.dtu.dk (S.M.) \\ 3 Laboratory of Computational Genomics, Department of Neurosciences, Biomedicine and Movement Sciences, \\ University of Verona, 37134 Verona, Italy; laura.veschetti@univr.it (L.V.); giovanni.malerba@univr.it (G.M.) \\ 4 Department of Clinical Microbiology, Rigshospitalet, 2100 Copenhagen, Denmark; hkj@biosustain.dtu.dk \\ 5 Department of Clinical Medicine, Faculty of Health and Medical Sciences, University of Copenhagen, \\ 2200 Copenhagen, Denmark \\ * Correspondence: maria.lleo@univr.it; Tel.: +39-045-802-7194 \\ + Equal contribution.
}

check for updates

Citation: Sandri, A.; Haagensen, J.A.J.; Veschetti, L.; Johansen, H.K.; Molin, S.; Malerba, G.; Signoretto, C.; Boaretti, M.; Lleo, M.M. Adaptive Interactions of Achromobacter spp. with Pseudomonas aeruginosa in Cystic Fibrosis Chronic Lung Co-Infection. Pathogens 2021, 10, 978. https:// doi.org/10.3390/pathogens10080978

Academic Editor: Linda D. Hazlett

Received: 2 June 2021

Accepted: 26 July 2021

Published: 3 August 2021

Publisher's Note: MDPI stays neutral with regard to jurisdictional claims in published maps and institutional affiliations.

Copyright: (c) 2021 by the authors. Licensee MDPI, Basel, Switzerland. This article is an open access article distributed under the terms and conditions of the Creative Commons Attribution (CC BY) license (https:// creativecommons.org/licenses/by/ $4.0 /)$.

\begin{abstract}
In the lungs of patients with cystic fibrosis (CF), the main pathogen Pseudomonas aeruginosa is often co-isolated with other microbes, likely engaging in inter-species interactions. In the case of chronic co-infections, this cohabitation can last for a long time and evolve over time, potentially contributing to the clinical outcome. Interactions involving the emerging pathogens Achromobacter spp. have only rarely been studied, reporting inhibition of $P$. aeruginosa biofilm formation. To evaluate the possible evolution of such interplay, we assessed the ability of Achromobacter spp. isolates to affect the biofilm formation of co-isolated $P$. aeruginosa strains during long-term chronic co-infections. We observed both competition and cohabitation. An Achromobacter sp. isolate secreted exoproducts interfering with the adhesion ability of a co-isolated P. aeruginosa strain and affected its biofilm formation. Conversely, a clonal Achromobacter sp. strain later isolated from the same patient, as well as two longitudinal strains from another patient, did not show similar competitive behavior against its P. aeruginosa co-isolates. Genetic variants supporting the higher virulence of the competitive Achromobacter sp. isolate were found in its genome. Our results confirm that both inter-species competition and cohabitation are represented during chronic co-infections in CF airways, and evolution of these interplays can happen even at the late stages of chronic infection.
\end{abstract}

Keywords: inter-species interactions; Achromobacter spp.; Pseudomonas aeruginosa; lung infection; cystic fibrosis

\section{Introduction}

Development of chronic lung infections and progressive inflammation is the major cause of morbidity and ultimate mortality for patients with cystic fibrosis (CF) [1]. Colonization with Pseudomonas aeruginosa, the most common pathogen isolated from CF airways, is particularly difficult to eradicate and is associated with an accelerated decline in lung function, with a poor prognosis [2]. Other respiratory pathogens play a role at different stages of the lung disease: Staphylococcus aureus and Haemophilus influenzae are the main pediatric pathogens, while Burkholderia cepacia complex, Achromobacter spp., Stenotrophomonas maltophilia and nontuberculous mycobacteria are mainly found in adults [3]. In particular, in the last decade, Achromobacter spp. gained attention as important emerging pathogens that can cause severe chronic infections in CF patients, associated with lung inflammation and decline in respiratory function [4-9] and further complicated by their innate and 
acquired multidrug resistance hindering eradication therapies $[10,11]$. The Achromobacter genus comprises 22 species [12]; Achromobacter xylosoxidans is the most often isolated species among CF patients, followed by Achromobacter ruhlandii, Achromobacter insuavis, Achromobacter insolitus, Achromobacter dolens, Achromobacter agrifaciens and Achromobacter spanius [7,13-17].

Due to the polymicrobial nature of CF lung infection, it is likely that microbes could engage in inter-species interactions, acting competitively or synergistically with each other to gain an adaptive advantage, thereby influencing the community composition, resistance to antibiotics and the course of airway disease $[18,19]$. In the case of chronic co-infections, this cohabitation can last for a long time and likely evolve. Interactions are usually favored by microbial proximity promoted by intra- and inter-species co-aggregation in biofilm communities [20,21]. The biofilm mode of growth, typical of CF chronic infections, allows bacteria to form highly organized, structured aggregates attached on the epithelial surface that protect the community from mechanical forces and penetration of chemicals [22,23]. Thus, biofilms decrease bacterial susceptibility to antimicrobial agents, promoting bacterial tolerance and/or resistance and favoring the failure of eradication therapies [24].

$P$. aeruginosa is often co-isolated with other microbial species sharing the same environment. While its interactions-including both cooperation and competition-with classical pathogens Burkholderia spp. and S. aureus have been extensively studied [25-32], the available information regarding interactions with emerging pathogens such as Achromobacter spp. and S. maltophilia is still limited. Despite the reported co-isolation of P. aeruginosa and Achromobacter spp. from sputum samples and the increasing number of patients becoming chronically infected with the latter $[6,9,33,34]$, thus far, only one recent study evaluated the occurrence of inter-species interactions between these two microorganisms, reporting that $P$. aeruginosa biofilm formation can be affected by $A$. xylosoxidans [35]. To evaluate the possible evolution of such interplay and its underlying mechanisms, in the present study, we assessed the ability of Achromobacter spp. isolates to affect the biofilm of P. aeruginosa strains sharing the same lung environment during long-term chronic co-infections and searched for genetic features of virulence possibly associated with the competition ability.

\section{Results}

P. aeruginosa and Achromobacter spp. clinical isolates were longitudinally collected from two CF patients chronically co-infected for over 9 years: patient A since 1996, and patient $B$ since 1999. For each patient, the two species were isolated from the same sputum sample twice: in 2005 and 2008 from patient A, and in 2008 and 2014 from patient B. The general information on each isolate is presented in Table 1. The genotypic relatedness of longitudinal isolates was verified by core genome similarity: P. aeruginosa isolates from patients A and B showed $82 \%$ and $83 \%$ similarity, respectively, while Achromobacter spp. isolates from both patients showed $87 \%$ similarity. While all Achromobacter spp. isolates had been initially identified as $A$. xylosoxidans [36], a recent phylogenetic analysis reclassified the isolates from patient $\mathrm{A}$ as $A$. insuavis [37]. The first $A$. insuavis strain collected from this patient, named isolate A1, was previously classified as a hypermutator [36]. P. aeruginosa isolates from patient A belong to the DK08 clone type, sampled from multiple patients at the Copenhagen CF Center [38]. 
Table 1. Identification and time of isolation of each clinical strain.

\begin{tabular}{ccccc}
\hline Patient & Isolate & Species & $\begin{array}{c}\text { Year of } \\
\text { Isolation }\end{array}$ & Other Characteristics \\
\hline A & A1 & A. insuavis & 2005 & Hypermutator \\
\hline A & P1 & P. aeruginosa & 2005 & DK08 clone type \\
\hline A & A2 & A. insuavis & 2008 & \\
\hline A & P2 & P. aeruginosa & 2008 & DK08 clone type \\
\hline B & A3* & A. xylosoxidans & 2008 & \\
\hline B & P3 & P. aeruginosa & 2008 & \\
\hline B & A4* & A. xylosoxidans & 2014 & \\
\hline B & P4 & P. aeruginosa & 2014 & \\
\hline
\end{tabular}

${ }^{*} \mathrm{~A} 3$ and $\mathrm{A} 4$ isolates were called B1 and B2 in a previous study [36].

\subsection{Phenotypic Variations}

To investigate possible phenotypic variations within the same host over time, we evaluated features such as growth rate and adhesion, which are known to often undergo modifications during bacterial adaptation into the CF lung. We previously observed that no significant changes in terms of growth rate and adhesion ability occurred over time within the longitudinal Achromobacter spp. isolates from the two patients [36]; growth curves are shown in Figure S2. On the contrary, P. aeruginosa isolates underwent the phenotypic evolution known to occur during CF chronic infection: the growth rate significantly diminished over time in both patients, while the adhesion ability increased significantly in patient A (Figure 1).
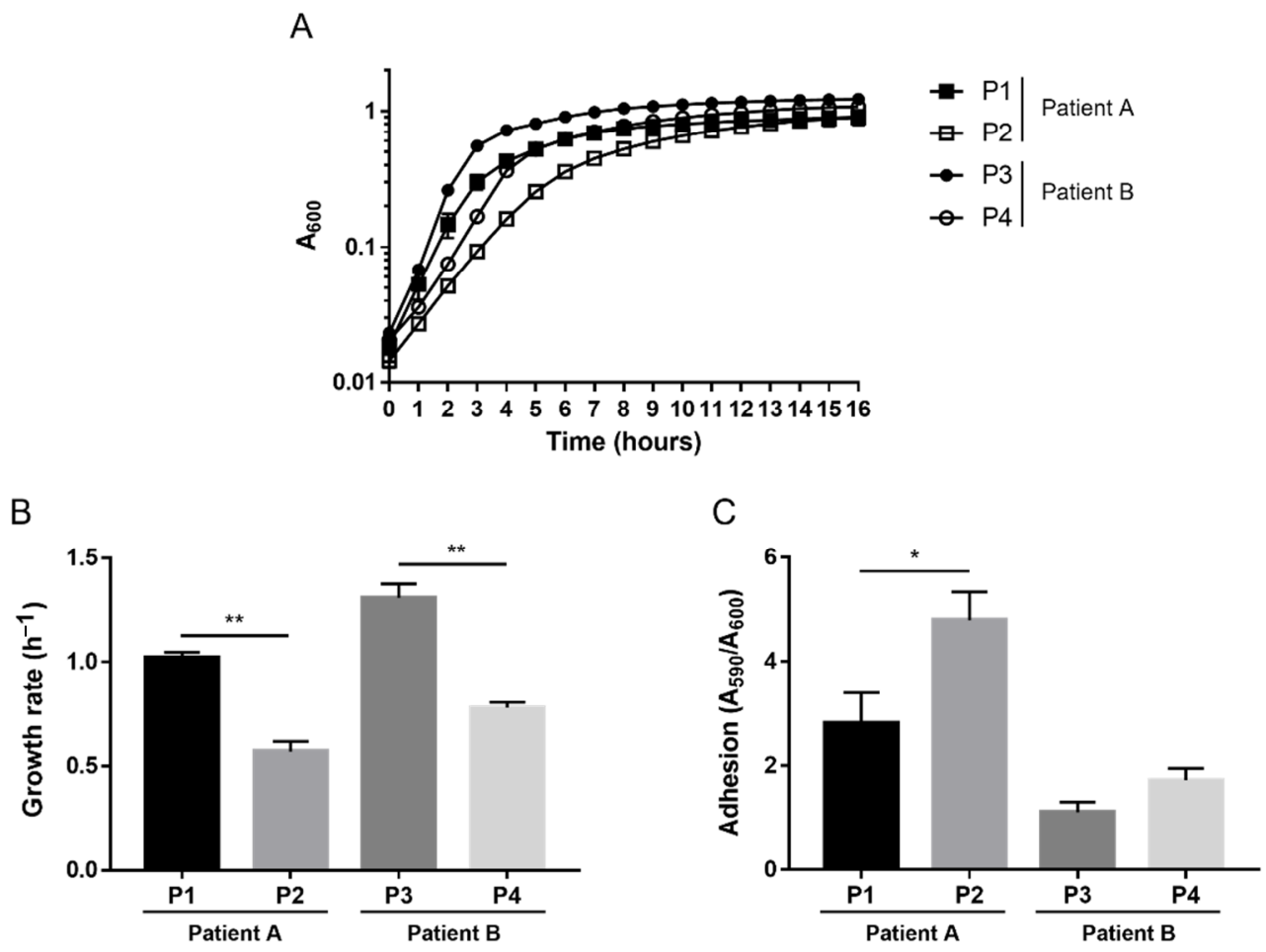

Figure 1. Growth curves (A), growth rate (B) and adhesion (C) of P. aeruginosa isolates. For growth curves, absorbance at $600 \mathrm{~nm}\left(\mathrm{~A}_{600}\right)$ was measured every hour for the first $16 \mathrm{~h}(\mathrm{~A})$. The growth rate was calculated from the exponential phase of growth curves $(B)$. Adhesion was measured by absorbance of crystal violet-stained surface-attached bacteria $\left(A_{590}\right)$ divided by absorbance of planktonic bacteria $\left(\mathrm{A}_{600}\right)(\mathrm{C})$. Each value represents the mean $\pm \mathrm{SEM}$ of three experiments. Statistical analysis was performed by $t$-test, ${ }^{*} p<0.05,{ }^{* *} p<0.01$. 


\subsection{Effects of Achromobacter spp. on P. aeruginosa Adhesion}

To investigate whether Achromobacter spp. isolates exhibited competition against $P$. aeruginosa, we first evaluated the potential effects on its adhesion. This is an essential ability for biofilm formation, which is considered a key feature for the successful colonization of $\mathrm{CF}$ lungs by $P$. aeruginos $a$ and other bacterial species. The adhesion of each P. aeruginosa strain was measured in the absence and presence of the culture supernatant collected from the co-isolated Achromobacter sp. strain. The culture supernatant contained all the exoproducts released during bacterial growth, including virulence factors; e.g., we previously observed a higher protease activity in an A1 culture supernatant than in supernatants from the other Achromobacter spp. isolates [36]. The P1 isolate showed a significantly lower adhesion ability when grown in the presence of A1 exoproducts (Figure 2). No such inhibitory effect was exhibited by the culture supernatants of the other Achromobacter spp. strains on their $P$. aeruginosa co-isolates, nor on the P. aeruginosa laboratory strain PAO1 (Figure S3).

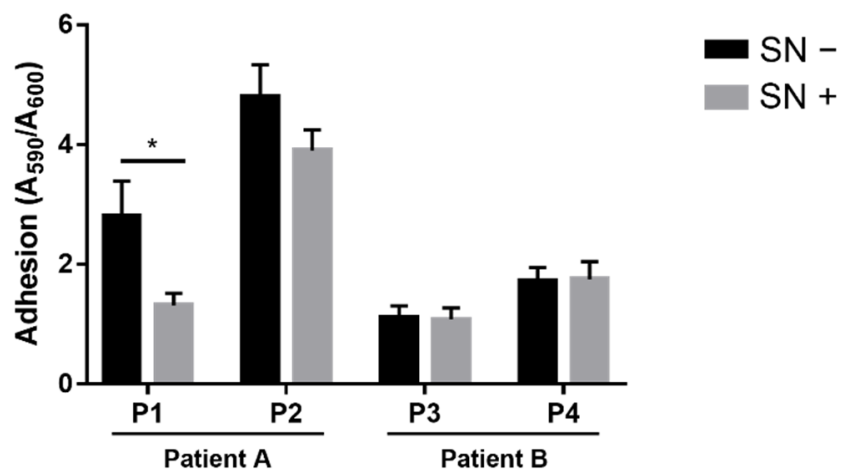

Figure 2. P. aeruginosa adhesion in the absence and presence of the co-isolated Achromobacter spp. culture supernatant $(\mathrm{SN}-, \mathrm{SN}+)$. Adhesion was measured by crystal violet staining of surfaceattached bacteria divided by $\mathrm{A}_{600}$ of planktonic bacteria. Each value represents the mean $\pm \mathrm{SEM}$ of 3 experiments. Statistical analysis was performed by $t$-test, ${ }^{*} p<0.05$.

\subsection{Effects of Achromobacter sp. on P. aeruginosa Biofilm Formation}

To investigate whether the A1 isolate could also inhibit $P$. aeruginosa biofilm formation, mixed biofilm cultures were grown in a flow chamber system for up to 5 days. To distinguish the two species, P. aeruginosa strains were tagged with the green fluorescent protein (GFP), and the fluorescence emission was checked (Figure S1). In single-species cultures, as expected, $P$. aeruginosa isolates could form big, stable aggregates firmly attached on the glass surface (Figure 3A,B). On the contrary, Achromobacter sp. strains showed a poor adhesion ability on glass, forming sporadic, unstable aggregates characterized by the scattering and dispersal of planktonic cells (Figure 3C). When the two microbes were cultured together, Achromobacter sp. could adhere and form mixed biofilms with P. aeruginosa. However, the Achromobacter sp. A1 isolate interfered with the biofilm formation of the co-isolated P. aeruginosa P1 strain. As shown in Figure 3D, P1 aggregates are smaller in the presence of A1, as also confirmed by the P. aeruginosa biomass quantification (Figure 3F). Such inhibitory effect was not observed in mixed biofilms formed by their longitudinal co-isolates A2 and P2 (Figure 3E). 
A

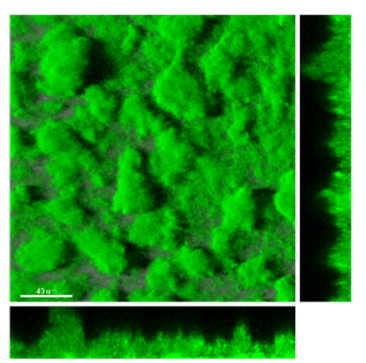

D

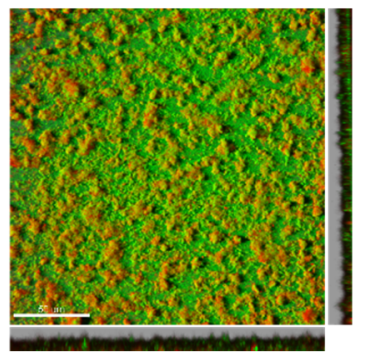

B

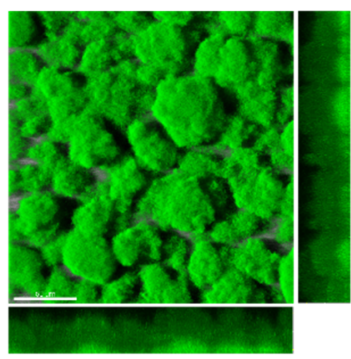

$E$

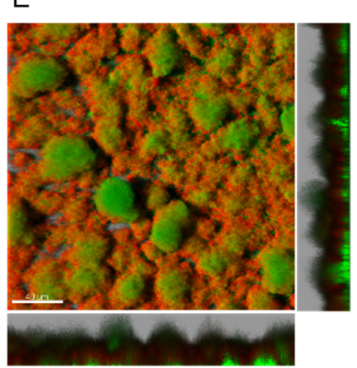

C

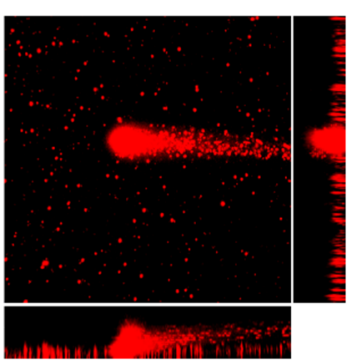

F

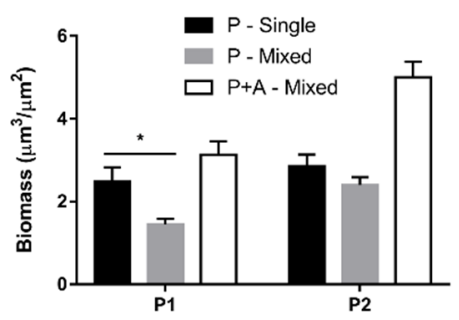

Figure 3. Single-species biofilms formed by P. aeruginosa P1 (A) and P2 (B) isolates, representative image of Achromobacter sp. biofilm structures (C), mixed biofilms formed by P1 + A1 (D) and P2 + A2 (E) strains and biomass quantification (F). Biofilms were grown in a flow chamber system for 5 days and monitored by confocal microscopy. P. aeruginosa isolates were tagged with GFP (green), and Achromobacter sp. cells were counterstained with Syto62 (red). P. aeruginosa biomass in single and mixed biofilms (P-Single, P-Mixed) and total biomass of mixed biofilms (P+A-Mixed) were calculated using Comstat 2 software. Each value represents the mean \pm SEM of 3 experiments. Statistical analysis was performed by the Mann-Whitney test, ${ }^{*} p<0.05$.

\subsection{Genetic Variants in Achromobacter sp. Virulence Genes}

Previously, we performed variant analysis of Achromobacter spp. isolates and observed that the A2, A3 and A4 genomes harbor no or few mutations, with a predicted high impact on protein function, while various frameshift mutations and a stop gain were detected in the A1 genome [36]. To find genetic evidence that could explain the observed inhibitory effect of the A1 isolate on the adhesion and biofilm formation of the P1 strain, we evaluated whether some of the genetic variants in the A1 genome involve genes related to virulence and inter-species competition. Interestingly, in A1, but not in the A2 genome, we detected the presence of a type VI secretion system tip protein, the VgrG gene, whose product is reported to bind antibacterial effectors targeting essential cell structures during interspecies competition between Gram-negative bacteria such as Acinetobacter baumannii [39]. Moreover, we found a stop gain in the HlyD family efflux transporter periplasmic adaptor subunit gene, whose product is a component of type I secretion systems involved in the secretion of virulence factors such as toxins and proteases [40]. When compared to the reference genome, this A1 gene results in a slightly shorter protein ( -15 amino acids), while for the A2 strain, the predicted length of the same gene product is largely reduced (-129 amino acids). Although no data are available regarding the effect of these variants on the protein function, we can hypothesize that the HlyD protein is more likely functional in the $\mathrm{A} 1$ rather than the $\mathrm{A} 2$ isolate.

\section{Discussion}

For a long time, CF lung infection has been studied and treated as a disease caused by a single pathogen, while, nowadays, we are aware of its polymicrobial nature [41,42]. Within microbial communities, intra- and inter-species interactions can take place and potentially influence the course of the infection $[18,19]$. Interactions involving the emerging pathogens Achromobacter spp. have only rarely been studied, probably because the clinical relevance of 
this microorganism became evident more recently. Nonetheless, their increased prevalence in CF and their frequent co-isolation with other pathogens such as $P$. aeruginosa suggest that Achromobacter spp. likely have to compete for space and nutrients [43]. In the case of chronic co-infections, where cohabitation can last for a long time, the evolution of such interplays might as well be part of the bacterial adaptation processes known to occur in CF airways. In the present investigation, we focused on Achromobacter spp.'s behavior towards $P$. aeruginosa within biofilm communities and observed both competition and cohabitation interplays during chronic co-infections.

As regards the biofilm mode of growth, Achromobacter spp. are motile (swimming) via long, peritrichous flagella but lack twitching motility $[44,45]$, which can contribute to the development of a surface-attached biofilm as it may help in stabilizing interactions with the surface [46]. Indeed, the poor adhesion ability of this microorganism in vitro (on polymeric surfaces within $48 \mathrm{~h}$ ) has been reported [45]. A reduction in surface attachment over time during infection was also shown in sequential CF isolates, in association with the acquisition of mutations in genes with a presumptive role in surface adhesion [47]. However, some studies highlighted Achromobacter spp.'s ability to adhere on hydrogel contact lenses $[48,49]$ and to form unattached or loosely attached aggregates held together by polysaccharides forming a peripheral shell around the bacterial cells $[45,50]$. Our current and previous [36] results confirm the poor adhesion ability of Achromobacter spp. on polystyrene and glass, and the formation of loosely attached aggregates characterized by the scattering and dispersal of planktonic cells. Interestingly, when cultured with $P$. aeruginosa, the two microbes could form mixed biofilms, suggesting that Achromobacter spp.'s adhesion might be enhanced on biotic surfaces.

Concerning inter-species interactions, we observed that only the A1 isolate has inhibitory effects against the co-isolated $P$. aeruginosa strain, interfering with its adhesion ability and affecting its biofilm formation capability. Conversely, the clonal strain A2 later isolated from the same patient, as well as two Achromobacter sp. strains longitudinally collected from another patient, did not show similar competitive behavior against their $P$. aeruginosa co-isolates. Thus far, only one recent study evaluated the occurrence of interspecies interactions between Achromobacter sp. and P. aeruginosa CF isolates, reporting that $P$. aeruginosa biofilm formation can be affected by $A$. xylosoxidans [35]. The isolate showing competition in our study belongs to a different species, A. insuavis, suggesting that this behavior might be common to various species of the genus. Interestingly, this isolate was previously classified as a hypermutator [36], and the isolates that Menetrey and colleagues observed to affect the P. aeruginosa biofilm were morphologically different clones collected from the same sputum sample of a chronically infected patient [35], a situation often exactly associated with the presence of hypermutators [51]. Although no genomic data are available from their study-limiting the evaluation of the hypermutation contribution - the association of this evolutionary mechanism with Achromobacter spp.'s competitive behavior should be further verified.

Investigating the genomic features that could be implicated in the observed competition, in the genome of the A1 isolate, we identified genetic variants supporting its higher virulence. Only in this isolate, we detected a type VI secretion system tip protein, the VgrG gene, whose product is known to be involved in inter-species competition between Gram-negative bacteria [39]. Additionally, $\operatorname{VgrG}$ paralogues have also been reported to regulate bacterial motility, biofilm formation and protease production in Aeromonas sp. [52]. Moreover, the A1 strain harbored a likely functional HlyD gene, while a deleterious variant was present in the genome of its clonal late isolate. HlyD is essential for the secretion of the RTX hemolytic toxin HlyA from Escherichia coli [53] and seems to be involved in the protease secretion mechanisms of P. aeruginosa [54]. We previously observed a higher protease secretion from the A1 strain in comparison to its clonal late isolate and to isolates from patient B [36], further supporting a higher expression of virulence traits in this isolate that could be involved in the observed competition against $P$. aeruginosa. Additionally, the genes related to the quorum sensing system were checked in all the P. aeruginosa isolates for the 
presence of variants, but no mutations were detected that could indicate down-regulation of this system.

Interestingly, 3 years after the A1 and P1 strains' isolation, their competitive interplay evolved towards a more indolent cohabitation or even cooperation-similar to the situation observed in patient B-which might represent a survival advantage. Although major adaptations of bacteria causing CF chronic infections are likely to happen during the early stage of chronic infection, while in the late stage, the situation is supposedly more stable, we observed variations in the interplay between two microorganisms in the late stage of a chronic co-infection, suggesting that adaptive mechanisms are still ongoing. In the later stage, isolates A2 and P2 could also grow together in mixed biofilm communities, supporting the possibility that close microbial interactions might occur between them. Indeed, bacterial proximity within biofilm communities can favor social exchanges of signal molecules and genetic elements, influencing many aspects of the community itself such as the microbial composition, nutrient availability, and antibiotic resistance [21]. Although the occurrence of close microbial interactions within the CF airway has not been demonstrated, in this particular case, their relevance should be considered: Achromobacter spp. are usually rich in mobile genetic elements carrying antibiotic resistance [11,55], whose exchange with and acquisition by other microbes such as $P$. aeruginosa might influence the course of infection and the outcome of antibiotic therapies.

In conclusion, despite our observations being limited to restricted mechanisms on a small number of selected strains, our results show that both inter-species competition and cohabitation are represented during chronic co-infections in CF airways, and evolution of these interplays can happen at the late stages of chronic infection. Furthermore, we provided insights on virulence mechanisms that could be involved in Achromobacter spp.'s competitive abilities. Future studies on a larger scale, involving more strains from more patients, are needed to better understand the interplay between competition and adaptation in the lungs of CF patients. Further mechanisms involved in inter-species interactions should also be explored, such as regulation of quorum sensing and secretion of specific virulence factors or metabolic by-products. In addition, evaluating interactions involving other microbial species would increase insights into the extent and complexity of such interplays and their contribution to the clinical outcome. This highlights the importance and necessity of further studies with a larger number of isolates, encouraging further research on this subject.

\section{Materials and Methods}

\subsection{Bacterial Isolates}

Four clinical isolates of Achromobacter spp. and P. aeruginosa were collected from two CF patients followed in the CF clinic at Rigshospitalet in Copenhagen, Denmark. The use of the stored bacterial isolates was approved by the local ethics committee at the Capital Region of Denmark (Region Hovedstaden) with the registration number H-4-2015-FSP. P. aeruginosa and Achromobacter spp. were isolated from the same sputum sample twice from each patient: in 2005 and 2008 from patient A, and in 2008 and 2014 from patient B.

\subsection{Growth Curves}

Bacterial strains were plated on LB agar and incubated at $37^{\circ} \mathrm{C}$ for $24-48 \mathrm{~h}$. One colony was picked from the plate and inoculated in $10 \mathrm{~mL} \mathrm{LB}$ medium, with shaking at $37^{\circ} \mathrm{C}$ overnight. Optical density at $600 \mathrm{~nm}\left(\mathrm{OD}_{600}\right)$ was measured using a spectrophotometer, cultures were diluted to $0.05 \mathrm{OD} / \mathrm{mL}$ in LB medium and $150 \mu \mathrm{L} /$ well was incubated in a 96-well plate for 20-24 h, with shaking at $37^{\circ} \mathrm{C}$. Using an automated plate reader, $\mathrm{OD}_{600}$ was measured every $20 \mathrm{~min}$. Growth rate was calculated using GraphPad Prism 7.0.

\subsection{Culture Supernatant Collection}

Achromobacter spp. strains were plated on LB agar and incubated at $37^{\circ} \mathrm{C}$ for $24-48 \mathrm{~h}$. One colony was picked from the plate and inoculated in $10 \mathrm{~mL}$ LB medium, with shaking 
at $37^{\circ} \mathrm{C}$ for $16 \mathrm{~h}$. $\mathrm{OD}_{600}$ was measured, and cultures were diluted to $0.1 \mathrm{OD} / \mathrm{mL}$ in $10 \mathrm{~mL}$ of LB medium. After shaking at $37^{\circ} \mathrm{C}$ for $16 \mathrm{~h}$, cultures were diluted to $1 \mathrm{OD} / \mathrm{mL}$ and centrifuged at $7000 \times g$ for $30 \mathrm{~min}$ at $4{ }^{\circ} \mathrm{C}$. Supernatants were collected and sterile filtered.

\subsection{Adhesion Assay}

Bacterial strains were plated on LB agar and incubated at $37{ }^{\circ} \mathrm{C}$ for $24-48 \mathrm{~h}$. One colony was picked from the plate and inoculated in $10 \mathrm{~mL}$ LB medium, with shaking at $37^{\circ} \mathrm{C}$ overnight. $\mathrm{OD}_{600}$ was measured using a spectrophotometer, cultures were diluted to $0.05 \mathrm{OD} / \mathrm{mL}$ in LB medium and $150 \mu \mathrm{L} /$ well was incubated in a 96-well plate for 20-24 h at $37^{\circ} \mathrm{C}$. After measuring $\mathrm{OD}_{600}$, wells were washed twice with water to remove unattached cells, and surface-attached cells were stained with $0.1 \%$ crystal violet solution for $15 \mathrm{~min}$. Wells were rinsed and washed three times with water and then dried for $1-2 \mathrm{~h}$. Thirty percent acetic acid was added, incubated at room temperature for $15 \mathrm{~min}$, and absorbance at $590 \mathrm{~nm}$ was measured. Adhesion measured by crystal violet staining (absorbance at $590 \mathrm{~nm}$ ) was normalized on growth (absorbance at $600 \mathrm{~nm}$ ). In competition assays, $P$. aeruginosa adhesion was measured in the presence/absence of $10 \%$ Achromobacter spp. culture supernatant.

\subsection{GFP Tagging}

$P$. aeruginosa strains were tagged with a mini-Tn7 construct carrying gentamycin resistance and GFPmut $3 b$ genes under the control of the growth-dependent $E$. coli ribosomal promoter $r r n B$ P1 [56]. The construct was introduced in P. aeruginosa by conjugative transfer as described by Choi and Schweizer [57]. Briefly, recipient $P$. aeruginosa strains were mixed with E. coli donor and helper strains (pRK2013 and pNTS2), and a drop of bacterial suspension was placed in the center of an LB agar plate and incubated at $37^{\circ} \mathrm{C}$ overnight. Transconjugants were selected by plating bacteria on LB agar containing gentamycin and trimethoprim. Mini-Tn7 insertion was checked by colony PCR using PTn7R and PglmSF primers [57]. To assess the growth-dependent fluorescence emission, P. aeruginosa GFPtagged strains were cultured in a 96-well plate for $12 \mathrm{~h}$, with shaking at $37^{\circ} \mathrm{C}$, while fluorescence (excitation $475 \mathrm{~nm}$, emission $520 \mathrm{~nm}$ ) and $\mathrm{OD}_{600}$ were measured every $20 \mathrm{~min}$ using an automated plate reader.

\subsection{Biofilm Formation Assay}

A flow chamber system was assembled and sterilized following the protocol from Tolker-Nielsen and Sternberg [58]. Briefly, $250 \mu \mathrm{L}$ of bacterial cultures $(0.05 \mathrm{OD} / \mathrm{mL})$ was injected in each flow cell channel. Flow cells were left upside-down for an hour without flow to let bacteria attach on the cover glass and then were turned and incubated at $30{ }^{\circ} \mathrm{C}$ for up to 5 days with flow (A10 minimal medium added with $\mathrm{MgCl}_{2}, \mathrm{CaCl}_{2}$ and trace metals). Biofilm formation was observed by confocal laser scanning microscopy for GFP-tagged cells and Syto62 staining of total cells. For statistical analysis, at least 7 pictures/channel were taken, homogeneously distributed along the channel. Pictures were visualized and elaborated using Imaris 7.4 software. Biomass was calculated using Comstat2 software [59].

\subsection{Genomic Analysis}

Whole genome sequencing and assembly were performed as previously described [36]. Sequences have been deposited at EMBL under the projects n. PRJEB35058 (Achromobacter spp. sequences) and PRJEB40978 (P. aeruginosa sequences). Sequence data can be found with the experiment accession numbers ERX3614542 (strain A1), ERX3614543 (strain A2), ERX3614548 (strain A3, previously called B1), ERX3614549 (strain A4, previously called B2), ERS5248144 (strain P1), ERS5248145 (strain P2), ERS5248146 (strain P3) and ERS5248147 (strain P4). Genotypic relatedness among longitudinal isolates was verified by checking core genome similarities obtained using the Harvest-OSX64-v1.1.2 suite [60]. Variant analysis was performed as previously described [36]. Briefly, two types of variant analysis were carried out: the first by aligning sequence reads to the reference genome, and the 
second by aligning them to the de novo assembly of the longitudinal isolate from the same patient. In the first case, the annotated genomes A. xylosoxidans NH44784-1996 and $P$. aeruginosa PAO1 (RefSeq accessions: GCF_000967095.2 and GCF_000006765.1) were used as reference genomes. Bowtie 2 v2.3.4.1 [61] was used for performing reads alignment, and the SnpEff v4.3t toolbox [62] was used to annotate variants and predict their functional effects. Only variants supported by a minimum of 20 reads were retained.

Supplementary Materials: The following are available online at https://www.mdpi.com/article/10 .3390/pathogens10080978/s1, Figure S1: Growth and fluorescence emission curves of GFP-tagged $P$. aeruginosa isolates; Figure S2: Growth curves of Achromobacter spp. isolates, Figure S3: Adhesion of $P$. aeruginosa PAO1 strain in absence and presence of the culture supernatants collected from the clinical Achromobacter spp. isolates.

Author Contributions: Conceptualization, A.S. and M.M.L.; methodology, A.S., J.A.J.H. and L.V.; validation, A.S., J.A.J.H. and L.V.; formal analysis, A.S., J.A.J.H. and L.V.; investigation, A.S.; resources, H.K.J., S.M., G.M. and M.M.L.; data curation, A.S. and L.V.; writing-original draft preparation, A.S.; writing-review and editing, J.A.J.H., L.V., H.K.J., S.M., G.M., C.S., M.B. and M.M.L.; visualization, A.S.; supervision, H.K.J., S.M., G.M., M.B. and M.M.L.; project administration, M.B. and M.M.L. All authors have read and agreed to the published version of the manuscript.

Funding: This research received no external funding.

Institutional Review Board Statement: The study was conducted according to the guidelines of the Declaration of Helsinki. The collection and use of the bacterial isolates used in this study were approved by the local Ethics Committee at the Capital Region of Denmark (Region Hovedstaden) with registration number $\mathrm{H}-4-2015-\mathrm{FSP}$.

Informed Consent Statement: Informed consent was obtained from all subjects involved in the study as approved by the Ethics Committee.

Data Availability Statement: Sequencing data are publicly available at EMBL under the projects $\mathrm{n}$. PRJEB35058 (Achromobacter spp. sequences) and PRJEB40978 (P. aeruginosa sequences).

Acknowledgments: We thank Alicia Jimenez Fernandez (Novo Nordisk Foundation Center for Biosustainability, Technical University of Denmark, Lyngby, Denmark), Alessia Ortombina and Debra Zanconato (Dept. of Diagnostics and Public Health, Section of Microbiology, University of Verona, Italy) for technical support. We thank the Technological Platform Center of the University of Verona for providing the computational platform used for sequence analysis.

Conflicts of Interest: The authors declare no conflict of interest.

\section{References}

1. Rowe, S.M.; Miller, S.; Sorscher, E.J. Cystic Fibrosis. N. Engl. J. Med. 2005, 352, 1992-2001. [CrossRef] [PubMed]

2. Pillarisetti, N.; Williamson, E.; Linnane, B.; Skoric, B.; Robertson, C.F.; Robinson, P.; Massie, J.; Hall, G.; Sly, P.; Stick, S.; et al. Infection, Inflammation, and Lung Function Decline in Infants with Cystic Fibrosis. Am. J. Respir. Crit. Care Med. 2011, $184,75-81$. [CrossRef]

3. Ciofu, O.; Hansen, C.R.; Høiby, N. Respiratory bacterial infections in cystic fibrosis. Curr. Opin. Pulm. Med. 2013, 19, 251-258. [CrossRef]

4. $\quad$ Aanaes, K.; Rickelt, L.F.; Johansen, H.K.; Von Buchwald, C.; Pressler, T.; Høiby, N.; Jensen, P.Ø. Decreased mucosal oxygen tension in the maxillary sinuses in patients with cystic fibrosis. J. Cyst. Fibros. 2011, 10, 114-120. [CrossRef]

5. Hansen, C.; Pressler, T.; Nielsen, K.G.; Jensen, P.Ø.; Bjarnsholt, T.; Høiby, N. Inflammation in Achromobacter xylosoxidans infected cystic fibrosis patients. J. Cyst. Fibros. 2010, 9, 51-58. [CrossRef] [PubMed]

6. Lambiase, A.; Catania, M.R.; Del Pezzo, M.; Rossano, F.; Terlizzi, V.; Sepe, A.; Raia, V. Achromobacter xylosoxidans respiratory tract infection in cystic fibrosis patients. Eur. J. Clin. Microbiol. Infect. Dis. 2011, 30, 973-980. [CrossRef]

7. Edwards, B.D.; Greysson-Wong, J.; Somayaji, R.; Waddell, B.; Whelan, F.J.; Storey, D.; Rabin, H.R.; Surette, M.G.; Parkins, M.D. Prevalence and Outcomes of Achromobacter Species Infections in Adults with Cystic Fibrosis: A North American Cohort Study. J. Clin. Microbiol. 2017, 55, 2074-2085. [CrossRef]

8. Firmida, M.; Pereira, R.; Silva, E.; Marques, E.; Lopes, A. Clinical impact of Achromobacter xylosoxidans colonization/infection in patients with cystic fibrosis. Braz. J. Med. Biol. Res. 2016, 49, 5097. [CrossRef]

9. Hansen, C.R.; Pressler, T.; Høiby, N.; Gormsen, M. Chronic infection with Achromobacter xylosoxidans in cystic fibrosis patients; a retrospective case control study. J. Cyst. Fibros. 2006, 5, 245-251. [CrossRef] 
10. Hu, Y.; Zhu, Y.; Ma, Y.; Liu, F.; Lu, N.; Yang, X.; Luan, C.; Yi, Y.; Zhu, B. Genomic Insights into Intrinsic and Acquired Drug Resistance Mechanisms in Achromobacter xylosoxidans. Antimicrob. Agents Chemother. 2014, 59, 1152-1161. [CrossRef]

11. Traglia, G.M.; Almuzara, M.; Merkier, A.K.; Adams, C.; Galanternik, L.; Vay, C.; Centron, D.; Ramírez, M.S. Achromobacter xylosoxidans: An Emerging Pathogen Carrying Different Elements Involved in Horizontal Genetic Transfer. Curr. Microbiol. 2012, 65, 673-678. [CrossRef]

12. Parte, A.C.; Carbasse, J.S.; Meier-Kolthoff, J.P.; Reimer, L.C.; Göker, M. List of Prokaryotic names with Standing in Nomenclature (LPSN) moves to the DSMZ. Int. J. Syst. Evol. Microbiol. 2020, 70, 5607-5612. [CrossRef]

13. Gade, S.S.; Nørskov-Lauritsen, N.; Ridderberg, W. Prevalence and species distribution of Achromobacter sp. cultured from cystic fibrosis patients attending the Aarhus centre in Denmark. J. Med. Microbiol. 2017, 66, 686-689. [CrossRef]

14. Papalia, M.; Steffanowski, C.; Traglia, G.M.; Almuzara, M.; Martina, P.; Galanternik, L.; Vay, C.; Gutkind, G.; Ramírez, M.S.; Radice, M. Diversity of Achromobacter species recovered from patients with cystic fibrosis, in Argentina. Rev. Argent. Microbiol. 2020, 52, 13-18. [CrossRef]

15. Spilker, T.; Vandamme, P.; LiPuma, J.J. Identification and distribution of Achromobacter species in cystic fibrosis. J. Cyst. Fibros. 2013, 12, 298-301. [CrossRef]

16. Barrado, L.; Brañas, P.; Orellana, M.D.L.A.; Martínez, M.T.; García, G.; Otero, J.R.; Chaves, F. Molecular Characterization of Achromobacter Isolates from Cystic Fibrosis and Non-Cystic Fibrosis Patients in Madrid, Spain. J. Clin. Microbiol. 2013, 51, 1927-1930. [CrossRef]

17. Amoureux, L.; Bador, J.; Zouak, F.B.; Chapuis, A.; de Curraize, C.; Neuwirth, C. Distribution of the species of Achromobacter in a French Cystic Fibrosis Centre and multilocus sequence typing analysis reveal the predominance of $A$. xylosoxidans and clonal relationships between some clinical and environmental isolates. J. Cyst. Fibros. 2016, 15, 486-494. [CrossRef]

18. McGuigan, L.; Callaghan, M. The evolving dynamics of the microbial community in the cystic fibrosis lung. Environ. Microbiol. 2015, 17, 16-28. [CrossRef]

19. Tashiro, Y.; Yawata, Y.; Toyofuku, M.; Uchiyama, H.; Nomura, N. Interspecies Interaction between Pseudomonas aeruginosa and Other Microorganisms. Microbes Environ. 2013, 28, 13-24. [CrossRef]

20. De Oliveira, R.V.D. Interactions among cariogenic bacterial species in oral biofilm. In The Battle against Microbial Pathogens: Basic Science, Technological Advances and Educational Programs; Méndez-Vilas, A., Ed.; Formatex Research Center: Badajoz, Spain, 2015; Volume 1, pp. 438-444.

21. Kuramitsu, H.K.; He, X.; Lux, R.; Anderson, M.H.; Shi, W. Interspecies Interactions within Oral Microbial Communities. Microbiol. Mol. Biol. Rev. 2007, 71, 653-670. [CrossRef]

22. Hall-Stoodley, L.; Stoodley, P. Evolving concepts in biofilm infections. Cell. Microbiol. 2009, 11, 1034-1043. [CrossRef]

23. Lieleg, O.; Caldara, M.; Baumgärtel, R.; Ribbeck, K. Mechanical robustness of Pseudomonas aeruginosa biofilms. Soft Matter 2011, 7, 3307-3314. [CrossRef] [PubMed]

24. Bjarnsholt, T. The role of bacterial biofilms in chronic infections. APMIS 2013, 121, 1-58. [CrossRef] [PubMed]

25. Lowery, C.A.; Park, J.; Gloeckner, C.; Meijler, M.M.; Mueller, R.S.; Boshoff, H.I.; Ulrich, R.L.; Barry, C.; Bartlett, D.H.; Kravchenko, V.V.; et al. Defining the Mode of Action of Tetramic Acid Antibacterials Derived from Pseudomonas aeruginosa Quorum Sensing Signals. J. Am. Chem. Soc. 2009, 131, 14473-14479. [CrossRef] [PubMed]

26. Yang, L.; Liu, Y.; Markussen, T.; Høiby, N.; Tolker-Nielsen, T.; Molin, S. Pattern differentiation in co-culture biofilms formed by Staphylococcus aureus and Pseudomonas aeruginosa. FEMS Immunol. Med. Microbiol. 2011, 62, 339-347. [CrossRef]

27. Hoffman, L.R.; Déziel, E.; D’Argenio, D.A.; Lepine, F.; Emerson, J.; McNamara, S.; Gibson, R.L.; Ramsey, B.W.; Miller, S.I. Selection for Staphylococcus aureus small-colony variants due to growth in the presence of Pseudomonas aeruginosa. Proc. Natl. Acad. Sci. USA 2006, 103, 19890-19895. [CrossRef]

28. Hubert, D.; Réglier-Poupet, H.; Sermet-Gaudelus, I.; Ferroni, A.; Le Bourgeois, M.; Burgel, P.R.; Serreau, P.R.; Dusser, D.; Poyart, C.; Coste, J. Association between Staphylococcus aureus alone or combined with Pseudomonas aeruginosa and the clinical condition of patients with cystic fibrosis. J. Cyst. Fibros. 2013, 12, 497-503. [CrossRef]

29. Chattoraj, S.S.; Murthy, R.; Ganesan, S.; Goldberg, J.B.; Zhao, Y.; Hershenson, M.B.; Sajjan, U.S. Pseudomonas aeruginosa Alginate Promotes Burkholderia cenocepacia Persistence in Cystic Fibrosis Transmembrane Conductance Regulator Knockout Mice. Infect. Immun. 2010, 78, 984-993. [CrossRef]

30. Bragonzi, A.; Farulla, I.; Paroni, M.; Twomey, K.B.; Pirone, L.; Lorè, N.I.; Bianconi, I.; Dalmastri, C.; Ryan, R.; Bevivino, A. Modelling Co-Infection of the Cystic Fibrosis Lung by Pseudomonas aeruginosa and Burkholderia cenocepacia Reveals Influences on Biofilm Formation and Host Response. PLoS ONE 2012, 7, e52330. [CrossRef]

31. El-Halfawy, O.; Valvano, M.A. Chemical Communication of Antibiotic Resistance by a Highly Resistant Subpopulation of Bacterial Cells. PLoS ONE 2013, 8, e68874. [CrossRef]

32. Bakkal, S.; Robinson, S.M.; Ordonez, C.L.; Waltz, D.A.; Riley, M.A. Role of bacteriocins in mediating interactions of bacterial isolates taken from cystic fibrosis patients. Microbiology 2010, 156, 2058-2067. [CrossRef]

33. De Baets, F.; Schelstraete, P.; Van Daele, S.; Haerynck, F.; Vaneechoutte, M. Achromobacter xylosoxidans in cystic fibrosis: Prevalence and clinical relevance. J. Cyst. Fibros. 2007, 6, 75-78. [CrossRef]

34. Tetart, M.; Wallet, F.; Kyheng, M.; Leroy, S.; Perez, T.; Le Rouzic, O.; Wallaert, B.; Prevotat, A. Impact of Achromobacter xylosoxidans isolation on the respiratory function of adult patients with cystic fibrosis. ERJ Open Res. 2019, 5, 5. [CrossRef] 
35. Menetrey, Q.; Dupont, C.; Chiron, R.; Jumas-Bilak, E.; Marchandin, H. High Occurrence of Bacterial Competition Among Clinically Documented Opportunistic Pathogens Including Achromobacter xylosoxidans in Cystic Fibrosis. Front. Microbiol. 2020, 11, 558160. [CrossRef] [PubMed]

36. Veschetti, L.; Sandri, A.; Johansen, H.K.; Lleò, M.M.; Malerba, G. Hypermutation as an Evolutionary Mechanism for Achromobacter xylosoxidans in Cystic Fibrosis Lung Infection. Pathogens 2020, 9, 72. [CrossRef]

37. Gabrielaite, M.; Nørskov-Lauritsen, N.; Nielsen, F.C.; Johansen, H.K.; Marvig, R.L. Genetic adaptation and transmission of Achromobacter in cystic fibrosis. bioRxiv 2020. [CrossRef]

38. Marvig, R.L.; Sommer, L.M.M.; Molin, S.; Johansen, H.K. Convergent evolution and adaptation of Pseudomonas aeruginosa within patients with cystic fibrosis. Nat. Genet. 2015, 47, 57-64. [CrossRef] [PubMed]

39. Lopez, J.; Ly, P.M.; Feldman, M.F. The Tip of the VgrG Spike Is Essential to Functional Type VI Secretion System Assembly in Acinetobacter baumannii. mBio 2020, 11, e02761-19. [CrossRef] [PubMed]

40. Thomas, S.; Holland, I.B.; Schmitt, L. The Type 1 secretion pathway-The hemolysin system and beyond. Biochim. Biophys. Acta (BBA) Bioenerg. 2014, 1843, 1629-1641. [CrossRef]

41. Rabin, H.R.; Surette, M.G. The cystic fibrosis airway microbiome. Curr. Opin. Pulm. Med. 2012, 18, 622-627. [CrossRef]

42. Lim, Y.W.; Evangelista, J.S.; Schmieder, R.; Bailey, B.; Haynes, M.; Furlan, M.; Maughan, H.; Edwards, R.; Rohwer, F.; Conrad, U.; et al. Clinical Insights from Metagenomic Analysis of Sputum Samples from Patients with Cystic Fibrosis. J. Clin. Microbiol. 2013, 52, 425-437. [CrossRef]

43. Magalhães, A.P.; Lopes, S.; Pereira, M.O. Insights into Cystic Fibrosis Polymicrobial Consortia: The Role of Species Interactions in Biofilm Development, Phenotype, and Response to In-Use Antibiotics. Front. Microbiol. 2017, 7, 2146. [CrossRef]

44. Trancassini, M.; Iebba, V.; Citerã, N.; Tuccio, V.; Magni, A.; Varesi, P.; De Biase, R.V.; Totino, V.; Santangelo, F.; Gagliardi, A.; et al. Outbreak of Achromobacter xylosoxidans in an Italian Cystic fibrosis center: Genome variability, biofilm production, antibiotic resistance, and motility in isolated strains. Front. Microbiol. 2014, 5, 138. [CrossRef] [PubMed]

45. Jakobsen, T.H.; Hansen, M.A.; Jensen, P.Ø.; Hansen, L.; Riber, L.; Cockburn, A.; Kolpen, M.; Hansen, C.R.; Ridderberg, W.; Eickhardt, S.; et al. Complete Genome Sequence of the Cystic Fibrosis Pathogen Achromobacter xylosoxidans NH44784-1996 Complies with Important Pathogenic Phenotypes. PLoS ONE 2013, 8, e68484. [CrossRef]

46. O'Toole, G.A.; Kolter, R. Flagellar and twitching motility are necessary forPseudomonas aeruginosabiofilm development. Mol. Microbiol. 1998, 30, 295-304. [CrossRef] [PubMed]

47. Ridderberg, W.; Nielsen, S.M.; Nørskov-Lauritsen, N. Genetic Adaptation of Achromobacter sp. during Persistence in the Lungs of Cystic Fibrosis Patients. PLoS ONE 2015, 10, e0136790. [CrossRef]

48. Dantam, J.; Subbaraman, L.N.; Jones, L. Adhesion of Pseudomonas aeruginosa, Achromobacter xylosoxidans, Delftia acidovorans, Stenotrophomonas maltophiliato contact lenses under the influence of an artificial tear solution. Biofouling 2020, 36, 32-43. [CrossRef] [PubMed]

49. Vijay, A.K.; Willcox, M. Adhesion of Stenotrophomonas maltophilia, Delftia acidovorans, and Achromobacter xylosoxidans to Contact Lenses. Eye Contact Lens Sci. Clin. Pract. 2018, 44, S120-S126. [CrossRef]

50. Nielsen, S.M.; Nørskov-Lauritsen, N.; Bjarnsholt, T.; Meyer, R.L. Achromobacter Species Isolated from Cystic Fibrosis Patients Reveal Distinctly Different Biofilm Morphotypes. Microorganisms 2016, 4, 33. [CrossRef] [PubMed]

51. Oliver, A.; Cantón, R.; Campo, P.; Baquero, F.; Blazquez, J. High Frequency of Hypermutable Pseudomonas aeruginosa in Cystic Fibrosis Lung Infection. Science 2000, 288, 1251-1253. [CrossRef]

52. Sha, J.; Rosenzweig, J.A.; Kozlova, E.V.; Wang, S.; Erova, T.E.; Kirtley, M.L.; van Lier, C.J.; Chopra, A.K. Evaluation of the roles played by Hcp and VgrG type 6 secretion system effectors in Aeromonas hydrophila SSU pathogenesis. Microbiology 2013, 159, 1120-1135. [CrossRef]

53. Pimenta, A.L.; Racher, K.; Jamieson, L.; Blight, M.A.; Holland, I.B. Mutations in HlyD, Part of the Type 1 Translocator for Hemolysin Secretion, Affect the Folding of the Secreted Toxin. J. Bacteriol. 2005, 187, 7471-7480. [CrossRef]

54. Guzzo, J.; Duong, F.; Wandersman, C.; Murgier, M.; Lazdunski, A. The secretion genes of Pseudomonas aeruginosa alkaline protease are functionally related to those of Erwinia chrysanthemi proteases and Escherichia coli?-haemolysin. Mol. Microbiol. 1991, 5, 447-453. [CrossRef] [PubMed]

55. Veschetti, L.; Sandri, A.; Patuzzo, C.; Melotti, P.; Malerba, G.; Lleò, M.M. Mobilome Analysis of Achromobacter spp. Isolates from Chronic and Occasional Lung Infection in Cystic Fibrosis Patients. Microorganisms 2021, 9, 130. [CrossRef]

56. Lambertsen, L.; Sternberg, C.; Molin, S. Mini-Tn7 transposons for site-specific tagging of bacteria with fluorescent proteins. Environ. Microbiol. 2004, 6, 726-732. [CrossRef] [PubMed]

57. Choi, K.-H.; Schweizer, H.P. mini-Tn7 insertion in bacteria with single attTn7 sites: Example Pseudomonas aeruginosa. Nat. Protoc. 2006, 1, 153-161. [CrossRef]

58. Tolker-Nielsen, T.; Sternberg, C. Growing and Analyzing Biofilms in Flow Chambers. Curr. Protoc. Microbiol. 2011, 21, 1B.2.11B.2.17. [CrossRef]

59. Heydorn, A.; Nielsen, A.T.; Hentzer, M.; Sternberg, C.; Givskov, M.; Ersbøll, B.K.; Molin, S. Quantification of biofilm structures by the novel computer program comstat. Microbiology 2000, 146, 2395-2407. [CrossRef] [PubMed]

60. Treangen, T.J.; Ondov, B.D.; Koren, S.; Phillippy, A. The Harvest suite for rapid core-genome alignment and visualization of thousands of intraspecific microbial genomes. Genome Biol. 2014, 15, 1-15. [CrossRef] 
61. Langmead, B.; Salzberg, S.L. Fast gapped-read alignment with Bowtie 2. Nat. Methods 2012, 9, 357-359. [CrossRef]

62. Cingolani, P.; Platts, A.; Wang, L.L.; Coon, M.; Nguyen, T.; Wang, L.; Land, S.J.; Lu, X.; Ruden, D.M. A program for annotating and predicting the effects of single nucleotide polymorphisms, SnpEff: SNPs in the genome of Drosophila melanogaster strain w1118; iso-2; iso-3. Fly 2012, 6, 80-92. [CrossRef] [PubMed] 